INVITED REVIEW

\title{
Lymphocytic hypophysitis: a rare or underestimated disease?
}

Antonio Bellastella, Antonio Bizzarro, Concetta Coronella, Giuseppe Bellastella, Antonio Agostino Sinisi and Annamaria De Bellis

Chair of Endocrinology, Department of Clinical and Experimental Medicine and Surgery, 'F. Magrassi, A. Lanzara', Second University of Naples, 5 Via S Pansini, 80131 Naples, Italy

(Correspondence should be addressed to A Bellastella; Email: antonio.bellastella@unina2.it)

\begin{abstract}
Lymphocytic hypophysitis (LYH) is an uncommon autoimmune disease in which the pituitary gland is infiltrated by lymphocytes, plasma cells and macrophages and its function is usually impaired. It has to be suspected in pregnant women and in women with recent delivery presenting with hyperprolactinemia, headache, visual field alterations and changes of one or more pituitary hormone secretions with secondary impairment of related peripheral target glands, especially when associated with other autoimmune endocrine or non-endocrine disorders. It can also occur less frequently in prepubertal or post-menopausal women and in men.

Headache, visual field impairment and more rarely diplopia are due to extrasellar pituitary enlargement with optic chiasma compression and/or to invasion of cavernous sinuses. Among the 'isolated' pituitary hormone deficiencies, ACTH deficit is usually the earliest and most frequent hormonal impairment and in rare cases can induce an acute secondary hyposurrenalism as the first sign of the disease, with high mortality in affected patients. Histopathological findings from pituitary biopsy show lymphoplasmacytic infiltrate with lymphoid aggregates surrounding atropic acini of pituitary cells; immunohistochemical analysis shows numerous mast cells randomly distributed and also localized in the vicinity of capillaries, suggesting a possible influence on capillary permeability and angiogenesis, thus favoring the inflammatory and immunological aggression against pituitary cells. Nuclear magnetic resonance imaging shows uniform sellar floor depression and an extrasellar symmetrical pituitary enlargement, usually displacing the optic chiasma, which shows a rapid homogeneous enhancement after gadolinium also involving the adjacent dura (dural tail). Antipituitary antibodies have been detected in several patients with LYH but their role needs to be clarified. Since a possible spontaneous remission can occur, a careful follow-up is required in subclinical patients without important hyposurrenalism or symptomatic extrasellar expansion. Medical (immunosuppressive, replacement and antiprolactinemic) and neurosurgical (decompression) treatments are needed in clinical symptomatic patients.
\end{abstract}

European Journal of Endocrinology 149 363-376

\section{Introduction}

Inflammatory processes of the hypophysis can be misdiagnosed because their clinical and radiological features mimic tumors in the sellar or parasellar region (1). They are classified as secondary when the inflammatory pituitary reaction is triggered by a definite etiologic infective agent or a known systemic disease, or primary when the inflammation is confined to the pituitary gland with no identifiable etiologic association (2).

Primary hypophysitis is histologically classified into three types (Table 1): lymphocytic hypophysitis (LYH), granulomatous hypophysitis (GRH), and xanthomatous hypophysitis $(\mathrm{XH})$. It is unclear whether these are truly distinct entities or only different expressions of the same disease, since they share clinical and radiological features and can only be distinguished from each other by histological examination. The characteristics of LYH will be clarified in the next sections. GRH is a granulomatous process involving the pituitary gland but not associated with other systemic chronic inflammatory diseases (3). The pathogenesis is still unclear: some authors suggest an autoimmune pathogenesis (4), others a viral etiology (5). GRH is characterized by pituitary infiltration of necrotizing granulomas that are formed by histiocytes and plasma cells surrounding areas of necrosis $(2,6-8)$. XH is an infiltrating process of the pituitary of unknown etiology consisting of foamy lipid-laden histiocytes with abundant clear cytoplasm and scattered lymphocytes (6, 9). Xanthogranulomatous hypophysitis (XGH) and necrotizing hypophysitis $(\mathrm{NH})$ are classified by some authors as further autonomous entities of hypophysitis (10); the first (XGH) is the same as $\mathrm{XH}$, reflecting only a variant terminology applied to xanthomatous 
inflammation at numerous body sites; the second (NH) usually involves the posterior lobe and only occasionally the anterior lobe of the pituitary. The affected patients show distinct clinical and radiological features including characteristic diabetes insipidus (11). In this context, we consider lymphocytic hypophysitis and lymphocytic adenohypophysitis as one and the same, but indicate lymphocytic-infundibulo-neurohypophysitis as an infiltrative and inflammatory process involving the posterior lobe of the pituitary and the infundibulum (12). Finally, we consider lymphocytic-infundibulohypophysitis to be an inflammatory process involving the anterior and posterior hypophysis and the infundibulum (13). Secondary hypophysitis (Table 1) encompasses inflammatory pituitary processes during several systemic inflammatory diseases such as Takayasu's disease (14), Crohn's disease (15), Langerhans cell histiocytosis (16), Wegener's granulomatosis (17), sarcoidosis (18), inflammatory pseudotumor (19) or those caused by defined bacterial, fungal and viral agents, including HIV (20).

Among the primary hypophysitis diseases described here we focus on LYH to clarify some ambiguous aspects of the disease which can contribute to misdiagnosis; lymphocytic-infundibulo-neurohypophysitis and lymphocytic-infundibulo-hypophysitis are usually easy to diagnose because of the concomitant partial or total diabetes insipidus and the characteristics at magnetic resonance imaging (MRI) (loss of post pituitary 'bright spot', see below).

\section{Lymphocytic hypophysitis}

Lymphocytic infiltration of endocrine glands, including the pituitary, does not always cause endocrine dysfunction since it can be observed at autopsies of patients who did not show functional alterations of the affected glands when they were alive $(21-23)$. Panhypopituitarism due to lymphoplasmacytic pituitary infiltration was described by Rapp and Pashkis in 1953 (24) but they could not classify this disorder as autoimmune

Table 1 Classification of hypophysitis.

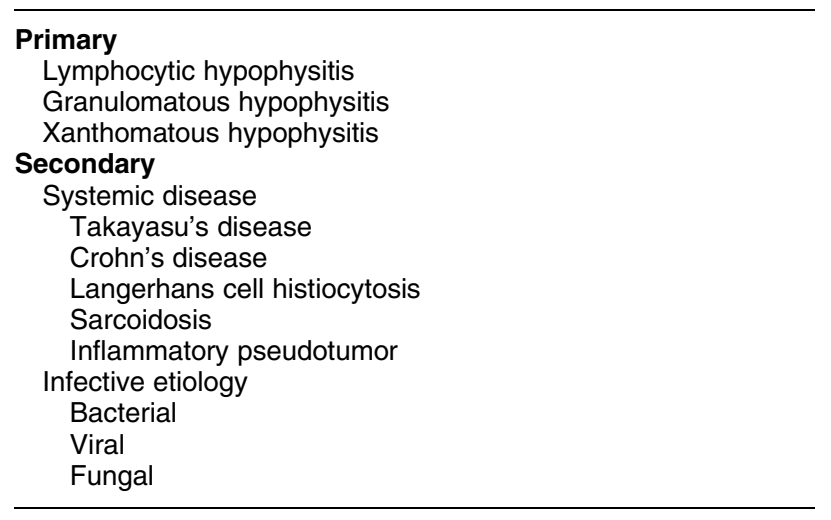

because the concept of endocrine autoimmunity was introduced some years later (25) for Hashimoto's thyroiditis, due to the coexistence in affected patients of lymphocytic thyroid infiltration and plasma thyroid autoantibodies. After the classification of Hashimoto's thyroiditis as an autoimmune endocrine disease, an autoimmune pathogenesis for LYH was suggested for the first time by Goudie and Pinkerton (26). They described the occurrence of post-partum amenorrhea and hypothyroidism in a young woman who subsequently died from severe acute secondary hyposurrenalism after appendicectomy. The autopsy revealed massive lymphoplasmacytic infiltration of both the pituitary and thyroid glands and adrenal atropy (26). After this first description (26) and before the introduction of pituitary biopsy and of MRI as diagnostic procedures, very few cases had been described in the literature (about 30 cases up to 1990) (5, 27-30). These were diagnosed on the basis of autoptical or post-hypophysectomy histopathological findings. Over the last 13 years the number of diagnosed cases has increased considerably, due probably to improved imaging criteria $(31,32)$, and over 200 cases have been diagnosed by 2003, considering only those cases where the inflammatory process involved only the anterior lobe of the pituitary, without affecting the posterior lobe $(2,3,13,31-64)$.

\section{Clinics and imaging of LYH}

An exhaustive review of the literature $(34,51)$ shows that women are affected more frequently than men with a ratio of about 5:1 (34) or 8:1 (51). The mean age at diagnosis is estimated as being 34.5 years for women and 44.7 years for men, although prepubertal $(42,65)$ or elderly cases have also been described (36, 53). LYH is rare in the Japanese population, but not in Caucasians with a Caucasian to Japanese ratio of about 3:1. However, although this assumption is based on the study of a large cohort of patients (38), it awaits epidemiologic confirmation to avoid a bias of case reporting. LYH seems to be strongly correlated with pregnancy, especially in the first large series of patients reported in the literature $(34,38)$. Usually, the first trimester of pregnancy is spared. Instead, LYH frequently affects women in the last six months of pregnancy and in the first six months after delivery $(34,38)$. However, in recent years reports of LYH cases occurring outside pregnancy have been on the increase. This suggests a higher prevalence than previously thought $(12,51,59-64)$. Usually, the affected patients have a family or their own history of autoimmunity. The most frequently described allele in the few patients in whom the study has been performed is HLA DR4, but HLA DR5 has also been found (38) (Table 2).

At the onset of the disease patients present symptoms and signs of extrasellar pituitary enlargement and only 
Table 2 General characteristics of lymphocytic hypophysitis.

Sex: F/M 8/1

Mean age at start of disease: $34.5(F)-44.7(\mathrm{M})$

Race: Caucasian/Japanese 3/1

Correlation with pregnancy: frequent appearance from 6 months before to 6 months after delivery

Familial or personal history of autoimmunity

HLA aplotype: HLA DR4 (44\%); HLA DR5 (23\%)

later do features of hypopituitarism become apparent (Table 3). Thus, headache is the first symptom. This usually precedes or is coupled with visual field impairment and, more rarely, diplopia due respectively to compression of the chiasma or invasion of cavernous sinuses by an enlarged pituitary mass (38). Hyperprolactinemia affects approximately one third of patients, causing amenorrhea/galactorrhea in women (39) and sexual dysfunction in men (65). However, it is underestimated in pregnant women and in women with recent delivery, whereas it is frequently ascribed to prolactinomas when occurring in men or in women outside of pregnancy $(51,60,66,67)$. Several causes have been suggested to explain hyperprolactinemia in LYH. Bottazzo et al. in 1975 (68) found autoantibodies to prolactin-secreting cells, suggesting a putative stimulating effect of these antibodies, but this assumption was not confirmed. Probably a multifactorial etiology related to the diffuse inflammatory process can be evoked for the hyperprolactinemia, namely loss of the inhibitory effect of dopamine and alteration of dopamine receptors, lactotrophe hyperplasia or escape of prolactin into the circulation secondary to the massive cellular destruction (1). Some patients with LYH can, however, present with hypoprolactinemia (32). Usually partial or total hypopituitarism is associated with alterations of prolactin secretion, even if pituitary function can be normal in some cases $(69,70)$. Thus, when LYH is suspected, basal and dynamic hormonal pituitary secretions have to be studied to disclose subclinical or overt alterations.

Table 3 Symptoms and signs of lymphocytic hypophysitis.

1. Related to the pituitary enlargement Headache (60\%)

Visual field impairment (40\%)

More rarely diplopia

2. Related to pituitary secretion alterations

Unusually normal pituitary function

Hyperprolactinemia (30\%)

More rarely hypoprolactinemia

Subclinical hypopituitarism (25\%)

ACTH deficiency (the earliest and most frequent isolated pituitary deficiency)

Rarely acute hyposurrenalism with high mortality

Hypogonadotropic hypogonadism (usually diagnosed only in males)

Rarely isolated $\mathrm{GH}$ deficiency
Among the 'isolated' pituitary hormone deficiencies, adrenocorticotropin (ACTH) deficiency is the earliest and most frequent alteration in patients with LYH. This is present in about $65 \%$ of cases (32); in rare cases it can induce acute secondary hyposurrenalism as the first appearance of the disease, with high mortality of affected patients $(27,71)$. LYH can also cause thyrotropin (TSH) and/or gonadotropin deficiencies (which are usually misdiagnosed when LYH affects women in pregnancy or in the postpartum period) whereas data on the effects on growth hormone/insulin-like growth factor-I (GH/IGF-I) secretions are scarce and inconclusive (38). A hypopituitarism involving almost all hormones usually occurs when the inflammatory process induces pituitary tissue destruction (38) (Table 3).

Imaging of LYH is particularly important to differentiate it from tumors in the sellar or parasellar region even if this is not always possible. X-ray, but mostly MRI, are useful for this purpose (Table 4). Radiographs reveal a usually flat sellar floor in LYH, but a unilaterally depressed one in pituitary adenomas. MRI has considerably improved the diagnostic accuracy of LYH by differentiating it from pituitary tumors $(13,31,57$, 70, 72). In fact, at MRI, patients with LYH show an enlarged pituitary with a symmetrical sovrasellar extension which displaces the optic chiasma (Fig. 1A,B), whereas patients with adenoma show asymmetrical pituitary enlargement with deviation of the stalk; the stalk is thickened but not usually deviated in LYH (31). The pituitary enhancement after injection of gadolinium is homogeneously intense in $\mathrm{LYH}$ and shows a strip of enhanced tissue along the dura madre (the so-called 'dural tail') (Fig. 1B,C); the enhancement can also involve the arachnoid (31). Patients with adenomas, on the other hand, show delayed and poor enhancement usually without a 'dural tail' after gadolinium. If the autoimmune process also involves the infundibulum and the neurohypophysis, causing a lymphocytic-infundibulo-hypophysitis or an infundibulo-neurohypophysitis, there is a loss of the 'bright spot'. Diabetes insipidus is usually present. In rare cases an empty sella can represent an unusual feature of LYH at MRI (72).

Despite the schematic criteria to differentiate LYH from pituitary adenoma described above and summarized in Table 4, findings from imaging tend to overlap. For this reason histopathological findings from pituitary biopsy remain the gold standard for diagnosing LYH (see next paragraph).

\section{Etiopathogenesis}

Although there is still some debate, an autoimmune pathogenesis is suggested by several histopathological, laboratory and clinical findings. The first histopathological observations were usually derived from autoptical or post-surgical pituitary examinations, whereas in more 
Table 4 Differences between lymphocytic hypophysitis (LYH) and pituitary adenoma using different imaging techniques.

\begin{tabular}{|c|c|c|}
\hline Imaging technique & LYH & Adenoma \\
\hline Sellar X-Ray & Sellar floor uniformly flat & Unilateral depression of sellar floor \\
\hline Pituitary NMR & $\begin{array}{l}\text { Pituitary enlargement with symmetrical sovrasellar } \\
\text { expansion } \\
\text { Compression and displacement of chiasma } \\
\text { Stalk thickened but not deviated }\end{array}$ & $\begin{array}{l}\text { Unilateral endosellar mass (microadenoma) or } \\
\text { inhomogeneously expanding pituitary mass with } \\
\text { asymmetrical sovrasellar extension (macroadenoma) } \\
\text { Contralateral deviation of stalk }\end{array}$ \\
\hline After gadolinium & $\begin{array}{l}\text { Intense and homogeneous enhancement of } \\
\text { pituitary mass } \\
\text { Appearance of 'dural tail' } \\
\text { Loss of 'bright spot' of neurohypophysis if diabetes } \\
\text { insipidus is associated }\end{array}$ & $\begin{array}{l}\text { Slight, delayed and inhomogeneous enhancement } \\
\text { Usually lack of 'dural tail' } \\
\text { Persistence of 'bright spot' }\end{array}$ \\
\hline
\end{tabular}
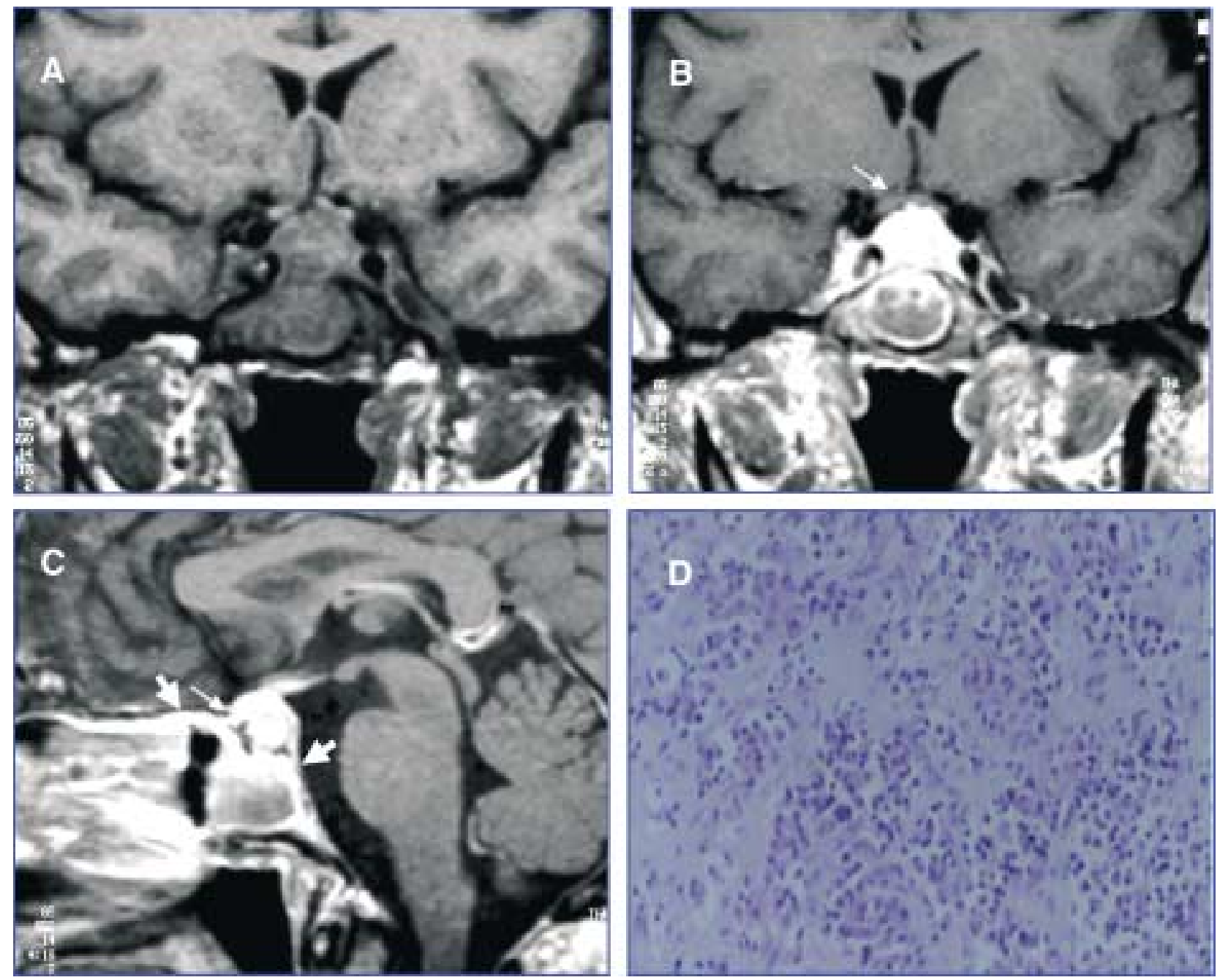

Figure 1 Radiological appearance on magnetic resonance (A, B, C) and histopathological findings (D) of lymphocytic hypophysitis. (Courtesy of Prof. Sossio Cirillo, Professor of Neuroradiology, Department of Neurological Science, 2nd University of Naples). Coronal precontrast (A) and postcontrast (B) T1-weighted images show a homogeneous pituitary mass with symmetrical sovrasellar extension compressing the optic chiasma (arrow in B). Coronal (B) and sagittal (C) postcontrast images show homogeneous enhancement of the pituitary mass, stalk, which appears thickened (thin arrow in C), and adjacent meningeal structures (thick arrows in C). (D) Lymphoplasmacytic aggregates surrounding atropic acini of pituitary cells. 
recent reports, specimens have been obtained by transsphenoidal pituitary biopsy which is thought to be the gold diagnostic standard for LYH.

The histopathological aspects are similar to those described for other endocrine glands involved in autoimmune processes $(73,74)$. In fact, the adenohypophysis is extensively infiltrated by lymphoplasmacytic cells, consisting of lymphocytes, plasma cells and macrophages (Fig 1D). T lymphocytes (of CD4 rather than CD8 class) are significantly more numerous than $\mathrm{B}$ lymphocytes $(34,38)$ and are sometimes arranged in lymphoid follicles with a germinal center. Lymphoplasmacytic aggregates surround atropic acini of pituitary cells (51), whereas the remaining pituitary tissue shows areas of reactive fibrosis $(51,69,75)$, but neither granulomas nor xanthomas $(51,76)$ are present. Immunohistochemical analysis shows numerous mast cells (77) and residual pituitary cells still containing the corresponding hormones (65). Mast cells are randomly distributed and also localized in the vicinity of capillaries. This could favor capillary permeability and angiogenesis, influencing the inflammatory and immunological aggression to pituitary cells (77). Although several autoimmune diseases are correlated to particular HLA alleles (78), HLA has been typed in a small sample of patients with LYH. The results are inconclusive. In fact, in 17 patients studied the predominant allele was the HLA DR4, followed less frequently by HLA DR 5 (38). However, in none of the patients studied did the pituitary cells express inappropriate HLA class II molecules (79) which have often been expressed in tissues affected by autoimmunity $(80,81)$.

The role of antipituitary antibodies (APAs) in LYH has yet to be clarified but their detection has amplified the diagnostic criteria, also suggesting a possible pathogenetic role. The methods used for detection have been the complement consumption test, immunofluorescence, immunoblotting, and radioligand assay.

The complement consumption test was the first method employed to detect pituitary autoantibodies (82). Testing against homogenates of human adenohypophysis plasma samples drawn during pregnancy, at delivery and in the immediate post-partum period from a large cohort of normal pregnant women, the authors detected antipituitary antibodies but only in the sera of $18 \%$ of women studied in the first week after delivery, of whom $25 \%$ proceeded towards pituitary insufficiency. In contrast, only $4 \%$ of women negative for antipituitary autoantibodies showed progression to pituitary insufficiency (82). However, following this report the method has not been employed by other laboratories.

The immunofluorescence method is one of the most widely used methods to detect pituitary autoantibodies $(28,68,83-87)$. Both human and animal pituitaries can be used as sources of tissue in which to detect APAs by this method. In the beginning, pituitaries were obtained from fetuses or corpses or after therapeutic hypophysectomy. Subsequently, presumably because of legal difficulties, several authors have had good results with pituitary glands from animals, in particular primates, guinea pigs or rats. Usually the animals undergo castration and thyroidectomy some weeks before pituitary ablation. Excellent results have been obtained using pituitaries from guinea pigs or rats (27). Results comparable to those obtained when using human glands have been reported by some authors employing pituitaries from primates (88), in particular from young baboons (87). Structurally, pituitary autoantigens are mostly lipoproteins and are located, like other endocrine autoantigens, in the intracellular membrane of the endoplasmic reticulum. The introduction of the four-layer immunofluorescence technique allowed investigators to identify autoantibodies reacting to several hormone-secreting pituitary cells (68). Using this tecnhique, the same pituitary section is tested consecutively against the patient's serum and the animal hormone antiserum. The different color of anti-Ig conjugate against the human serum and against the animal serum, respectively green (FITC) and red (rhodamine), allows direct visual assessment of whether the patient's serum and the animal's anti-hormone serum stain the same or different pituitary cells. Since the two sera are directed against different antigens, the immunofluorescence produced by the patient's autoantibodies is not prevented by the hormone antiserum and vice versa. This is confirmed by the lack of variation of cytoplasmic staining when human positive serum is preabsorbed with an excess of the appropriate hormone (83). Screening a cohort of autoimmune polyendocrine patients, Bottazzo et al. first detected antipituitary autoantibodies (68) using as substrate sections of human pituitaries obtained surgically by hypophysectomy from patients with breast cancer, whose pituitary is markedly hypertropic and hyperplastic. They showed a positive immunoreactivity in $12 \%$ of sera investigated involving only a confined group of pituitary cells. These have subsequently been recognized as prolactin (PRL)-secreting cells by a four-layer immunofluorescence technique (68). These antibodies belonged to the class of IgM but in most cases also to classes IgG and IgA. When the same technique was used on a larger series of patients, the same and other authors $(28,89-92)$ confirmed the detection of PRL-cell antibodies, mainly in patients with autoimmune polyendocrinopathies (about $12.6 \%$ of 420 patients tested) and with lower prevalence in patients with single autoimmune endocrinopathies $(2.3 \%$ of 587 patients tested) except for patients with autoimmune hypoparathyroidism (92), who showed the highest prevalence of PRL-cell autoantibodies (about $23.3 \%$ of 86 patients tested). None of the patients positive for PRL-cell autoantibodies showed clinical signs of pituitary dysfunction. However, a potential pathogenetic role of these antibodies in autoimmune hypophysitis seems to be suggested by a report 
regarding a woman with Addison's disease: the presence of PRL-cell antibodies without alterations of pituitary function when she was alive, but with histopathological findings of adenohypophysitis (pituitary lymphoplasmacytic infiltration) at post-mortem autopsy (90) seem to indicate that these antibodies could play a pathogenetic role in the initial (subclinical) stage of autoimmune aggression. Even if PRL-cell autoantibodies were the first to be detected by immunofluorescence, antibodies to other pituitary hormoneproducing cells were subsequently detected. In particular, antibodies to ACTH-secreting cells were detected in some patients with isolated ACTH deficiency $(29,93)$ and in $25 \%$ of patients with Cushing's disease (85). In these latter patients, they seem to favor the relapse of pituitary tumor, suggesting a stimulating action on the ACTH-secreting cells in Cushing's disease (85). On the contrary, in patients with ACTH deficiency, ACTH-cell autoantibodies seem to be directed against a $70 \mathrm{kDa}$ enzyme, aspartil protease, which catalyzes the conversion of proopiomelanocortin to ACTH (93) even if in these patients autoantibodies directed to the surface of pituitary cell lines have also been detected (94).

Autoantibodies to GH-secreting cells were first detected by Bottazzo et al. (84) in a patient with Turner's syndrome, partial GH deficiency and a familial history of autoimmune polyendocrinopathy (Schmidt's syndrome in the mother). These antibodies have also been detected in only three out of 397 prepubertal subjects with idiopathic short stature (29) and in one out of four patients with idiopathic GH deficiency (28). Thus their role in these disorders still has to be clarified.

Autoantibodies staining all the cells from animal pituitary cells were detected in patients with Sheehan's syndrome (28), in some patients with type 1 diabetes mellitus $(86,91)$ and in some of their relatives free from disease (91). However, none of the APA-positive diabetic patients had altered pituitary function $(86,91)$. Antipituitary antibodies directed against a 49-kDa autoantigen in patients with Sheehan's syndrome have recently been confirmed. This suggests that pituitary autoimmunity may play a pathogenetic role in the hypopituitarism following postpartum hemorrhage (95), even taking into account the fact that pituitary autoantibodies can be the result of antigen exposure following pituitary necrosis rather than being the cause of pituitary impairment.

The immunoblotting method introduced by Crock et al. in 1990 (96) is a specific method to detect antipituitary antibodies. They tested the sera of some patients with idiopathic or secondary GH deficiency and some normal subjects against cytosolic and membrane autoantigens prepared from post-mortem human pituitaries. One of 19 patients with idiopathic $\mathrm{GH}$ deficiency precipitated a $45-\mathrm{kDa}$ membrane protein, an antigen thought to be pituitary specific, and another precipitated a 43-kDa cytosol protein, an antigen diffusely represented in the brain. Among patients with acquired GH deficiency, one out of 14 showed autoantibodies to a $45-\mathrm{kDa}$ antigen while three showed antibodies to a $95-\mathrm{kDa}$ membrane protein. None of the sera from the control group was positive $(96,97)$. The same authors lent further support to the hypothesis of an autoimmune pathogenesis of LYH, studying a large cohort of biopsy-proven or suspected patients with this disease. They found a high prevalence $(70 \%)$ of precipitation against a $49-\mathrm{kDa}$ cytosolic protein in sera from patients with biopsyproven LYH and a lower but nevertheless significant prevalence $(55 \%)$ in sera from patients with suspected LYH. However, the same precipitation was observed in $10 \%$ of controls, in $15 \%$ of patients with thyroid autoimmunity, in $42 \%$ of patients with Addison's disease and in $13 \%$ of those with rheumatoid arthritis (98). Moreover, $50 \%$ of sera from patients with biopsyproven LYH and 30\% of sera from those with suspected LYH precipitated another autoantigen, a 40-kDa cytosolic protein, also precipitated by $10 \%$ of the sera from controls but by none of the sera from patients with pituitary tumors or other autoimmune diseases. Immunoprecipitation against the $49-\mathrm{kDa}$ protein was also observed in two out of three studied patients with isolated ACTH deficiency. Since an ACTH deficiency frequently occurs at an early stage of LYH, because ACTH-secreting cells are the first ones damaged by the inflammatory process, the authors suggested that the $49-\mathrm{kDa}$ antigen may be released by these damaged cells, thus evoking the immune response with production of the corresponding autoantibodies. In light of this they concluded that although this antigen is not specific because it is present in several tissues of different species, it can be considered an important serological marker of autoimmunity both for isolated ACTH deficiency and for LYH (98). In a more recent paper, the 49-kDa autoantigen associated with LYH was purified and identified as alpha-enolase (99). The autoantigen was purified from monkey brain and human placental cytosol. Limited amino acid sequencing after proteolytic digestion of the human placental protein showed identity with alphaenolase. The identification was confirmed using sera from patients with pituitary autoimmunity, which strongly reacted with recombinant human alpha-enolase, indicating that the immunoreactive epitopes are largely conserved from yeast to human. The authors concluded that alpha-enolase, even if not specific for pituitary but widely represented in human and animal tissues, is the first autoantigen isolated in LYH (99). It can be considered one of the targets of APAs, in the same way that 21-hydroxylase can be identified as one of the targets of adrenocortical autoantibodies in autoimmune Addison's disease (87, 100). Moreover, gamma-enolase, an enolase subunit known as neuron-specific enolase (NSE) and normally expressed in the pituitary, has also recently been demonstrated in the placenta (101). In fact, sera from patients with 
LYH reacted with both pituitary and placental NSE (i.e. gamma-enolase). The autoimmune response evoked by an antigen shared between the pituitary and the placenta seems to provide a theoretical basis for the strong prediliction of LYH to occur during or after pregnancy (101).

On the other hand, pituitary autoantibodies against a 22-kDa antigen from porcine pituitary have been detected in $57 \%$ of patients with type 1 and in $24 \%$ of patients with type 2 diabetes mellitus without $\mathrm{LYH}$ (102). Thus, concerning the clinical significance, probably some APAs can be harmless, whereas others can activate intracellular signaling and exert a biological function $(87,103)$.

Autoantibodies against some pituitary hormones have been detected in several conditions (104-109). In particular, antibodies against TSH in patients with Graves' disease $(104,105)$, against follicle-stimulating hormone and luteinizing hormone $(\mathrm{LH})$ in patients with premature ovarian failure (106), against GH in patients with short stature (107) and in those with GH deficiency (108), against alpha-melanocyte-stimulating hormone (MSH), ACTH and LH releasing hormone in patients with anorexia or bulimia nervosa (109) have been detected but their pathological significance remains to be seen.

The radioligand assay is a method recently employed in patients with LYH to investigate the presence of autoantibodies against three specific pituitary proteins, GH and two novel pituitary-specific proteins, namely pituitary gland specific factor 1a (PGSF1a) and 2 (PGSF2) (110). The presence of each antibody was studied by radioligand assay, using human S-labeled protein. Eighteen percent of patients with LYH with pituitary enlargement, $36 \%$ of patients with hypopituitarism without pituitary enlargement and $9.7 \%$ of patients with other autoimmune disease, but no patients with non-functioning pituitary adenoma, were positive for one or more of the antibodies studied, suggesting that the detection of these antibodies may be useful for the diagnosis of LYH (110).

Another argument advanced in favor of the autoimmune pathogenesis of LYH is the frequent association with other endocrine or non-endocrine autoimmune diseases. The most common association with endocrine autoimmune disease is with Hashimoto's thyroiditis or Graves' disease (111), but other described associations are with type 2 diabetes mellitus, Addison's disease, parathyroiditis, pernicious anemia, and chronic atropic gastritis $(55,65,112)$. Less frequently, LYH has been described as associated with lupus erythematosus $(35,49)$, erythema nodosus (48), germinoma (41), dacryoadenitis (43), idiopathic retroperitoneal fibrosis (113), asymptomatic primary biliary cirrhosis (36), and autoimmune polyglandular syndrome (APS) type $1(48,114)$ or, more frequently, type 3a $(73,74,87)$ (Fig. 2).

The natural history of LYH is also similar to other autoimmune endocrine diseases $(73,115)$, progressing through several stages $(5,73)$ in which the different histopathological features are paralleled with corresponding clinical aspects. At disease onset the pituitary gland is enlarged, edematous and with lymphocytic infiltration, putting pressure on adjacent structures. This leads to headache, visual field impairment and, more rarely, diplopia. At this stage a sub-clinical hypopituitarism can be present and may be disclosed with appropriate dynamic studies but a spontaneous

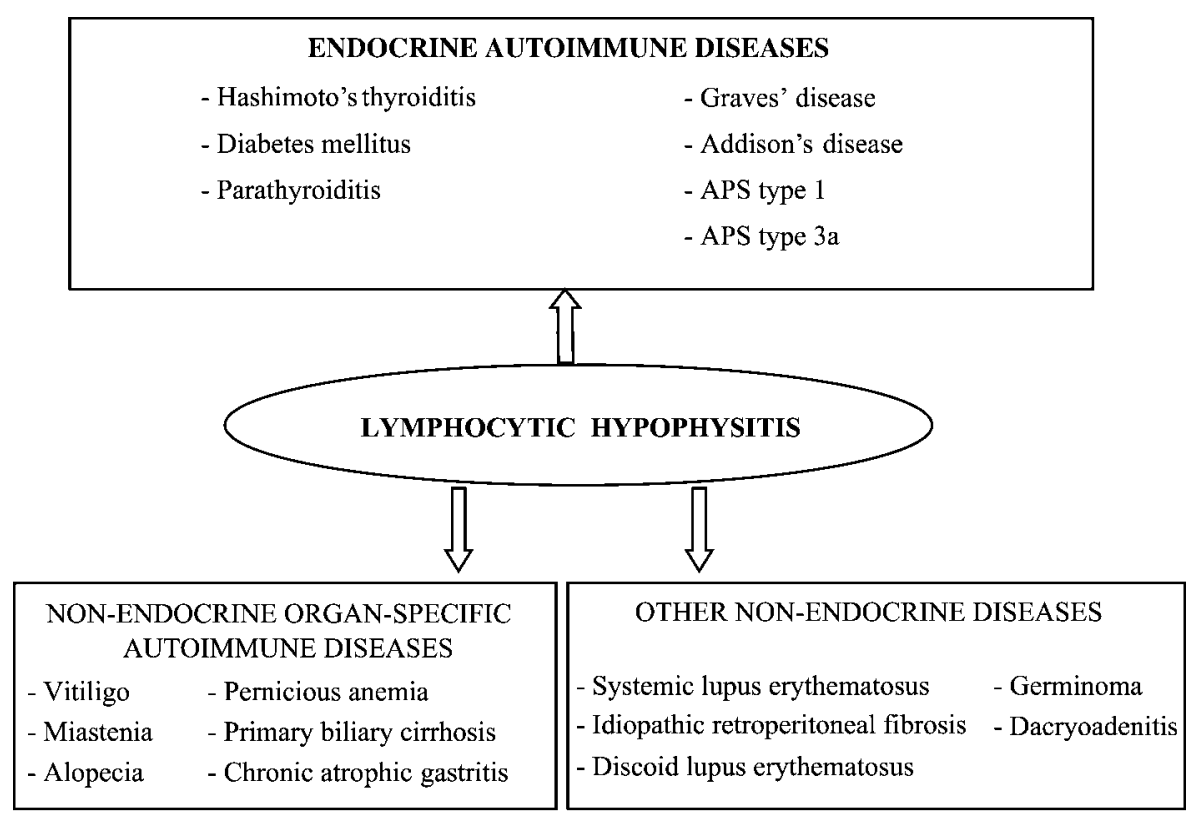

Figure 2 Lymphocytic hypophysitis can be associated with autoimmune endocrine and non-endocrine diseases. 
remission can occur if the pituitary tissue is not destroyed. In a subsequent stage, the pituitary parenchyma, destroyed by the inflammatory process, is substituted with fibrous tissue, progressing sometimes to atropy. At this stage, symptoms of partial or total hypopituitarism usually appear (5). In conclusion, a putative autoimmune pathogenetic mechanism can be hypothesized taking into account the interrelationships between the hypothalamic-pituitary-adrenal (HPA) axis and the mediators of inflammatory process evoked by the autoimmune aggression $(21,116,117)$ (Fig. 3). Usually, in the course of the immune inflammatory process, some cytokines produced at inflammatory sites stimulate the HPA axis leading to its hyperactivation, which contributes to the extinction of the same inflammatory process. In fact, corticotropin releasing hormone (CRH) together with arginine vasopressin (AVP) induce the release of pituitary ACTH which stimulates cortisol secretion from the adrenal gland. AVP can also directly stimulate cortisol production by the adrenal gland, via V3 receptors (117). Cortisol exerts an inhibiting action on the inflammatory and immune processes. For this reason both AVP and ACTH can be considered neurohormones influencing both immune and inflammatory processes (118).

The disruption of the cytokine-HPA axis circuit can predispose to autoimmunity (119). In LYH when the immune aggression causes important damage to the pituitary cells, mostly ACTH-secreting cells in the early stage, the secondary reduced secretion of cortisol is not able to interrupt the immune process, thus perpetuating its aggression to pituitary cells with consequent stable pituitary dysfunction.

When the cell damage is transient because it is related mostly to the pituitary edema, the rapid normalization of the pituitary-adrenal axis secretion interrupts the immune inflammatory process inducing spontaneous recovery of pituitary function. Conversely, when the immune inflammatory process also involves the hypothalamus and neurohypophysis, cortisol secretion is highly impaired, due to the lack of both ACTH and AVP stimuli. If this aggression is massive it can induce a precocious adrenal atropy which could explain the rare cases where an acute secondary hyposurrenalism can occur as the first appearance of the disease, with high mortality in affected patients $(29,71)$.

\section{Diagnosis of LYH}

The gold standard for the diagnosis of LYH in patients with the above-described clinical symptoms is a histopathological study by pituitary biopsy showing the peculiar lymphoplasmacytic infiltration. However, NMR imaging and detection of antipituitary antibodies have improved the diagnostic procedures allowing LYH detection at a subclinical stage in patients with other autoimmune diseases or with apparently

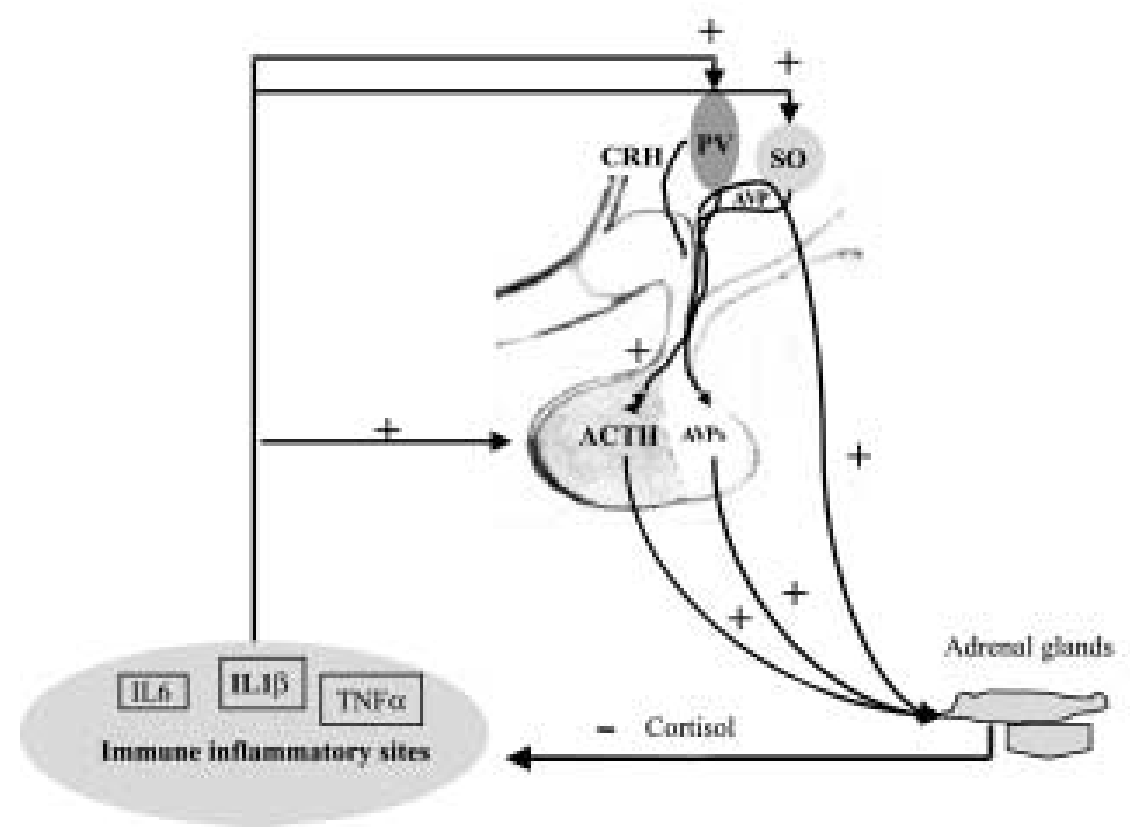

Figure 3 Reciprocal interrelationships between AVP, CRH-ACTH-cortisol axis and cytokines released from immune inflammatory sites. Cytokines released from inflammatory sites stimulate hypothalamic $\mathrm{CRH}$ and probably also AVP. CRH, together with AVP, induces the release of pituitary $\mathrm{ACTH}$, which stimulates cortisol secretion from the adrenal gland. Cortisol, whose secretion can also be directly stimulated by AVP, dampens the inflammatory response by inhibiting cytokine production. PV, paraventricular nucleus; SO, supraoptic nucleus; AVPs, AVP storage in post-pituitary; IL-6, interleukin 6; IL-1b, interleukin 1b; TNF $\alpha$, tumor necrosis factor $\alpha$. 
idiopathic pituitary dysfunctions. Since ACTH-secreting cells seem to be the first pituitary cells damaged by the autoimmune inflammatory process, several authors have looked for the presence of antipituitary antibodies both in isolated ACTH deficiency and in LYH, also indicating their possible diagnostic and/or pathogenetic role $(27,93,98)$. On the other hand, the occurrence of pituitary autoantibodies and their role in patients with idiopathic GH deficiency is still discussed (28, 96, 108, 110, 120). As previously reported, Crock et al., testing the sera of some patients with idiopathic or secondary GH deficiency against cytosol and membrane autoantigens, detected antibodies to such antigens not only in two out of 19 patients with idiopathic GH deficiency, but also in four out of 14 patients with acquired GH deficiency (96).

Following our studies on GH-deficiency (GHD) in adults (121-123) we used an immunofluorescence method to investigate the presence of APAs in adults with apparently idiopathic GHD and in patients with acquired GHD in order to verify the prevalence of pituitary autoimmunity in these patients. Moreover, we studied 180 patients with organ-specific autoimmune diseases to evaluate the prevalence of APA-positive patients and to correlate the presence of APAs to their pituitary functional state and particularly to $\mathrm{GH}$ secretion (87).

APAs were found at high titers in four of 12 patients with apparently idiopathic GHD but in none of the patients with acquired GHD. APAs were also found in 40 of 180 patients with autoimmune organ-specific diseases $(22.2 \%), 35$ of them at low titers $(87.5 \%)$, and five at high titers (12.5\%). Autoimmune APAnegative patients and all APA-positive patients at low titers had normal pituitary function, whereas all APApositive patients at high titers had a severe isolated GHD (Fig. 4). With respect to the characteristics of the hypothalamus and sellar regions, among the five autoimmune patients positive for APA at high titers, three showed normal imaging, one showed imaging suggestive of infundibulo-hypophysitis (pituitary enlargement with enhancement after gadolinium, pituitary stalk thickening and absence of bright spot) and another had a partial empty sella, which can be an unusual feature of LYH at MRI (72). Our results suggest that APAs, when detected at high titers, are

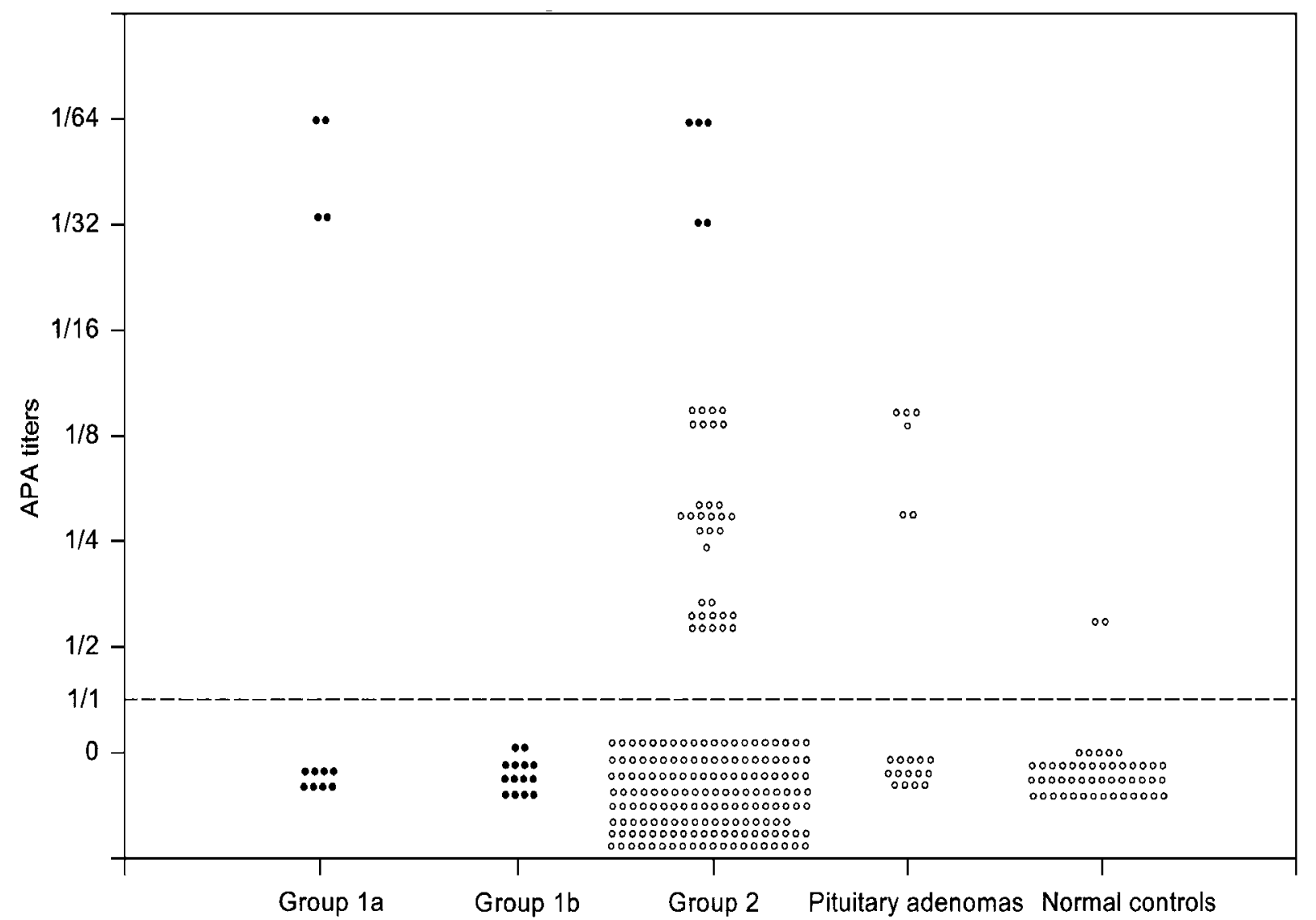

Figure 4 Behavior of APAs in adults with childhood-onset idiopathic GH deficiency (group 1a) and adults with GHD secondary to surgery for pituitary and parasellar tumor (group 1b), patients with autoimmune endocrine disease (group 2), patients with pituitary adenomas and normal controls. The black circles indicate patients with GHD diagnosed by impaired response to insulin tolerance test and arginine test. From De Bellis et al. (87) with permission from Evelyn M Frazier, Journals Coordinator of the Endocrine Society. 
a good diagnostic tool to reveal the occurrence of GHD in adults with autoimmune endocrine diseases. Moreover, they may indicate an autoimmune pituitary involvement in adults with apparently idiopathic GHD, suggesting that the prevalence of autoimmune GHD is much higher than that so far considered (87).

\section{Therapeutic strategy}

The natural history of LYH indicates that it can evolve in different ways, thus requiring different therapeutic strategies. Since a possible spontaneous remission can occur $(42,124-127)$ a careful follow-up is advisable in subclinical patients without important hyposurrenalism nor symptomatic extrasellar expansion. Surgical transsphenoidal treatment, with an intrasurgical cryostatic slide to confirm diagnosis and to save possible viable pituitary tissue, is required in patients with symptoms and/or signs of severe compression $(61,81)$. In some cases pituitary biopsy is both diagnostic and therapeutic, because after this procedure a progressive recovery of pituitary function can be observed (2).

Glucocorticoids or other anti-inflammatory and immunosuppressive (methotrexate, cyclosporin A) drugs have been suggested as medical treatment but their long-term efficacy still needs to be confirmed. High-dose methylprednisolone pulse therapy seems to be effective in about $30 \%$ of treated patients (128). Recently, a young woman suffering from severe visual disturbance 3 months after delivery was diagnosed as having an LYH. Her MRI revealed a pituitary mass with an extension into the suprasellar cistern, with intense and homogeneous enhancement after gadolinium. She was treated with high-dose methylprednisolone pulse therapy (64). Her visual disturbance dramatically ameliorated on the first day of treatment and MRI revealed marked mass reduction, whereas pituitary function completely recovered 6 months after therapy (64).

Positive results have also been reported using cyclosporin A in a patient with LYH and APS type 1 (48). Bromocriptine, a dopamine agonist, can improve visual field alterations and lower hyperprolactinemia but the beneficial impact of this agent on the course of the disease is unproven (2). Stable hypopituitarism in the course of LYH or due to the neurosurgical therapy has to be appropriately corrected with replacement hormone therapy. Finally, data on the so-called 'isohormonal therapy', whose effectiveness in restoring some hormonal subclinical dysfunction in other autoimmune endocrine diseases has been demonstrated (129-132), are lacking in LYH. Such therapy utilizes hormonal products of the gland affected by the immune process to influence this process at the preclinical stage, when the affected gland is not completely and irreversibly destroyed, and it may act by feedback inhibition of glandular function or by determining suppression of autoimmunity or by a combination of both mechanisms (130, 133). A longitudinal study of patients positive for APAs treated at the stage of subclinical hypopituitarism could be useful to clarify this aspect.

\section{Acknowledgements}

We are very indebted to Professor Gian Franco Bottazzo, Scientific Directorate, Ospedale Pediatrico Bambin Gesù, Roma, Italy and Professor Corrado Betterle, Chair of Clinical Immunology and Allergy, University of Padua, Padua, Italy, whose reviews on the endocrine autoimmunity have been a great help for the draft of this manuscript.

This work was supported in part by grants from Ministero Istruzione, Università e Ricerca (PRIN 2001 1063439-003 to A Bellastella).

\section{References}

1 Thodou E, Asa SL, Kontogeorgos G, Kovacs K, Horvath E \& Ezzat S. Lymphocytic hypophysitis: clinicopathological findings. Journal of Clinical Endocrinology and Metabolism $1995 \mathbf{8 0}$ 2302-2311.

2 Cheung CC, Ezzat S, Smyth HS \& Asa SL. The spectrum and significance of primary hypophysitis. Journal of Clinical Endocrinology and Metabolism 200186 1048-1053.

3 Sautner D, Saeger W, Ludecke DK, Jansen V \& Puchner MJ. Hypophysitis in surgical and autoptical specimens. Acta Neuropathologica $199590637-644$.

4 Hassoun P, Anayssi E \& Salti I. A case of granulomatous hypophysitis with hypopituitarism and minimal pituitary enlargement. Journal of Neurology, Neurosurgery and Psychiatry 1985 48 949-951.

5 Cosman F, Post KD, Holub DA \& Wardlaw SL. Lymphocytic hypophysitis. Report of 3 new cases and review of the literature. Medicine 198968 240-256.

6 Asa SL. Tumors of the Pituitary Gland. Third series, fascicle 22. Washington, DC: Armed Forces Institute of Pathology, 1998.

7 Scanarini M, d'Ercole AJ, Rotilio A, Kitromilis N \& Mingrino S. Giant-cell granulomatous hypophysitis: a distinct clinicopathological entity. Journal of Neurosurgery 198971 681-686.

8 Vasile M, Marsot-Dupuch K, Kujas M, Brunereau L, Bouchard P, Comoy J et al. Idiopathic granulomatous hypophysitis: clinical and imaging features. Neuroradiology 199739 7-11.

9 Folkerth RD, Price DL Jr, Schwartz M, Black PM \& De Girolami U. Xanthomatous hypophysitis. American Journal of Surgical Pathology 199822 736-741.

10 Tashiro T, Sano T, Xu B, Wakatsuki S, Kagawa N, Nishioka H et al. Spectrum of different types of hypophysitis: a clinicopathologic study of hypophysitis in 31 cases. Endocrine Pathology 2002 13 183-195.

11 Ahmed SR, Aiello DP, Page R, Hopper K, Towfighi J \& Santen RJ. Necrotizing infundibulo-hypophysitis: a unique syndrome of diabetes insipidus and hypopituitarism. Journal of Clinical Endocrinology and Metabolism 199376 1499-1504.

12 Maghnie M, Genovese E, Sommaruga MG, Arico M, Locatelli D, Arbustini E et al. Evolution of childhood central diabetes insipidus into panhypopituitarism with a large hypothalamic mass: is 'lymphocytic infundibuloneurohypophysitis' in children a different entity? European Journal of Endocrinology 1998139 635-640.

13 Sato N, Sze G \& Endo K. Hypophysitis: endocrinologic and dynamic MR findings. American Journal of Neuroradiology 1998 19 439-444. 
14 Toth M, Szabo P, Racz K, Szende B, Balogh I, Czirjak S et al. Granulomatous hypophysitis associated with Takayasu's disease. Clinical Endocrinolgy 199645 499-503.

15 De Bruin WI, van't Verlaat JW, Graamans K \& de Bruin TW. Sellar granulomatous mass in a pregnant woman with active Crohn's disease. Netherlands Journal of Medicine 199139 136-141.

16 Vadakekalam J, Stamos T \& Shenker Y. Sometimes the hooves do belong to zebras! An unusual case of hypopituitarism. Journal of Clinical Endocrinology and Metabolism 199580 17-20.

17 Goyal M, Kucharczyk W \& Keystone E. Granulomatous hypophysitis due to Wegener's granulomatosis. American Journal of Neuroradiology 200021 1466-1469.

18 Bullmann C, Faust M, Hoffmann A, Heppner C, Jockenhovel F, Muller-Wieland D et al. Five cases with central diabetes insipidus and hypogonadism as first presentation of neurosarcoidosis. European Journal of Endocrinology 2000142 365-372.

19 Hansen I, Petrossians P, Thiry A, Flandroy P, Gaillard RC, Kovacs $\mathrm{K}$ et al. Extensive inflammatory pseudotumor of the pituitary. Journal of Clinical Endocrinology and Metabolism 2001 86 4603-4610.

20 Sano T, Kovacs K, Scheithauer BW, Rosenblum MK, Petito CK \& Greco CM. Pituitary pathology in acquired immunodeficiency syndrome. Archives of Pathology and Laboratory Medicine 1989 113 1066-1070.

21 Basteine PA. Recent contributions to the immunology of thyroid pathology. Bruxelles Medical 197656 393-398.

22 Hayashi Y, Hiyoshi T, Takemura T, Kurashima C \& Hirokawa K. Focal lymphocytic infiltration in the adrenal cortex of the elderly: immunohistological analysis of infiltrating lymphocytes. Clinical and Experimental Immunology 198977 101-105.

23 Shanklin WM. Lymphocytes and lymphoid tissue in the human pituitary. Anatomical Record 195111 177-191.

24 Rapp JJ \& Pashkis KE. Panhypopituitarism with idiopathic hypoparathyroidism. Annals of Internal Medicine $1953391103-1107$.

25 Roitt IM, Doniach D, Campbell PN \& Hudson RV. Autoantibodies in Hashimoto's disease. Lancet 19562 820-822.

26 Goudie EB \& Pinkerton PH. Anterior hypophysitis and Hashimoto's disease in a young woman. Journal of Pathology and Bacteriology $1962 \mathbf{8 3} 584-585$.

27 Asa SL, Bilbao JM, Kovacs K, Josse RG \& Kreines K. Lymphocytic hypophysitis of pregnancy resulting in hypopituitarism: a distinct clinicopathologic entity. Annals of Internal Medicine 1981 $95166-171$.

28 Pouplard A. Pituitary autoimmunity. Hormone Research 198216 289-297.

29 Mauerhoff T, Mirakian R \& Bottazzo GF. Autoimmunity and the pituitary. In Endocrine and Other Organ-Oriented Autoimmune Disorders, pp 217-235. Eds D Doniach \& G-F Bottazzo. Bailliere's Clinical Immunology and Allergy, 1987.

30 Quencer RM. Lymphocytic adenohypophysitis: autoimmune disorder of the pituitary gland. American Journal of Neuroradiology $19801343-345$.

31 Ahmadi J, Scott Myers G, Segall HD, Sharma OP \& Hinton DR. Lymphocytic adenohypophysitis: contrast-enhanced MR imaging in five cases. Radiology 1995195 30-34.

32 Abe T, Matsumoto K, Sanno N \& Osamura Y. Lymphocytic hypophysitis: case report. Neurosurgery 199536 1016-1019.

33 Riedl M, Czech T, Slootweg J, Czernin S, Hainfellner JA, Schima $\mathrm{W}$ et al. Lymphocytic hypophysitis presenting as pituitary tumor in a 63-year-old man. Endocrine Pathology $19956159-166$.

34 Hashimoto K, Takao T \& Makino S. Lymphocytic adenohypophysitis and lymphocytic infundibuloneurohypophysitis. Endocrine Journal $1997 \mathbf{4 4} 1-10$.

35 Katano H, Umemura A, Kamiya K, Kanai H \& Yamada K. Visual disturbance by lymphocytic hypophysitis in a non pregnant woman with systemic lupus erythematosus. Lupus 19987 $554-556$
36 Nishiki M, Murakami Y, Koshimura K, Sohmiya M, Tanaka J, Yabe $\mathrm{S}$ et al. A case of autoimmune hypophysitis associated with asymptomatic primary biliary cirrhosis. Endocrine Journal $199845697-700$.

37 Verdu LI, Martin-Caballero C, Garcia-Lopez G \& Cueto MJ. Ovulation induction and normal pregnancy after panhypopituitarism due to lymphocytic hypophysitis. Obstetrics and Gynecology $199891850-852$.

38 Beressi N, Beressi JP, Cohen R \& Modigliani E. Lymphocytic hypophysitis. A review of 145 cases. Annals of Internal Medicine 1999 $150327-341$.

39 Echevarria G, Gonorazky S, Gaspari M \& Sundblad A. Idiopathic hypophysitis in elderly patients. Report of 2 cases and review of literature. Revista de Neurologia 199929 1175-1179.

40 Farah JO, Rossi M, Foy PM \& MacFarlane IA. Cystic lymphocytic hypophysitis, visual field defects and hypopituitarism. International Journal of Clinical Practice 199953 643-644.

41 Fehn M, Bettendorf M, Ludecke DK, Sommer C \& Saeger W. Lymphocytic hypophysitis masking a suprasellar germinoma in a 12-year-old girl - a case report. Pituitary 19991 303-307.

42 Gagneja H, Arafah B \& Taylor HC. Histologically proven lymphocytic hypophysitis: spontaneous resolution and subsequent pregnancy. Mayo Clinic Proceedings 199974 150-154.

43 Joussen AM, Sommer C, Flechtenmacher C \& Voelcker HE. Lymphocytic hypophysitis associated with dacryoadenitis: an autoimmunologically mediated syndrome. Archives of Ophthalmology $1999117959-962$.

44 Kamel N, Ilgin SD, Gullu S, Tonyukuk VC \& Deda H. Lymphocytic hypophysitis and infundibuloneurohypophysitis; clinical and pathological evaluations. Endocrine Journal 1999 46 505-512.

45 Murakami H, Hirose Y, Sagoh M \& Hayashi T. Probable lymphocytic hypophysitis diagnosed by short-term serial computed tomography and gallium-67 scintigraphy: case report. Neurologia Medico - Chirurgica 199939 174-178.

46 Ozbey N, Kahraman H, Yilmaz L, Orhan Y, Sencer E \& Molvalilar S. Clinical course of a pituitary macroadenoma in the first trimester of pregnancy: probable lymphocytic hypophysitis. International Journal of Clinical Practice 199953 478-481.

47 Ruelle A, Bernasconi D, Tunesi G \& Andrioli G. Lymphocytic hypophysitis. Case report. Journal of Neurosurgery Sciences 1999 43 205-208.

48 Ward L, Paquette J, Seidman E, Huot C, Alvarez F, Crock P et al. Severe autoimmune polyendocrinopathy-candidiasis-ectodermal dystrophy in an adolescent girl with a novel AIRE mutation: response to immunosuppressive therapy. Journal of Clinical Endocrinology and Metabolism 199984 844-852.

49 Ji JD, Lee SY, Choi SJ, Lee YH \& Song GG. Lymphocytic hypophysitis in a patient with systemic lupus erythematosus. Clinical and Experimental Rheumatology $2000 \mathbf{1 8} 78-80$.

50 Pinol V, Cubiella J, Navasa M, Fernandez J, Halperin I, Bruguera $\mathrm{M}$ et al. Autoimmune hepatitis associated with thyroiditis and hypophysitis. A case report. Journal of Gastroenterology and Hepatology 200023 123-125.

51 Duràn Martìnez M, Santonja C, Pavon de Paz I \& Monereo Megias S. Lymphocytic hypophysitis: report of an unusual case of a rare disorder. Journal of Endocrinological Investigation 200124 190-193.

52 Krimholtz MJ, Thomas S, Bingham J \& Powrie JK. Lymphocytic hypophysitis: spontaneous resolution on MRI with progression of endocrine defect. Internal Journal of Clinical Practice 200155 339-340.

53 Nakamura Y, Okada H, Wada Y, Kajiyama K \& Koshiyama H. Lymphocytic hypophysitis: its expanding features. Journal of Endocrinological Investigation $200124262-267$.

54 Noto H, Tsukamoto K, Hayashi S, Takano K, Fujita T \& Kimura S. Spontaneous recovery from hypopituitarism in a man with lymphocytic hypophysitis: a case report. Endocrine Journal $200148483-486$. 
55 Novoa-Takara L, Cornford M, Williams C \& Tayek JA. Lymphocytic hypophysitis in a man presenting with hypercalcemia. American Journal of the Medical Sciences $2001321206-208$.

56 Tubridy N, Molloy J, Saunders D, Belli A, Powell M \& Plant GT. Postpartum pituitary hypophysitis. Journal of Neuro-Ophthalmology 200121 106-108.

57 Folkerth RD, Price DL Jr, Schwartz M, Black PM \& De Girolami U. Xanthomatous hypophysitis. American Journal of Surgical Pathology 199822 736-741.

58 Chelaifa K, Bouzaidi K, Harzallah F, Menif E, Ben Messaoud M, Turki I et al. Lymphocytic hypophysitis. Journal of Neuroradiology 200229 57-60.

59 Dan N, Feiner R, Houang M \& Turner J. Pituitary apoplexy in association with lymphocytic hypophysitis. Journal of Clinical Neuroscience 2002 9 577-580.

60 Matta MP, Kany M, Delisle MB, Lagarrigue J \& Caron PH. A relapsing remitting lymphocytic hypophysitis. Pituitary 2002 5 37-44.

61 Skandarajah A, Ng W, Gonzales M \& Kaye A. Lymphocytic hypophysitis mimicking pituitary macroadenoma. Journal of Clinical Neuroscience $20029586-589$.

62 Hansen I, Betea D \& Beckers A. Inflammatory diseases of the pituitary during pregnancy. Annales d'Endocrinologie 200263 464-469.

63 Chung HK, Kim DH, Kim SJ, Park BJ, Kim EJ, Myong NH et al. First male case of lymphocytic hypophysitis in Korea. Journal of Korean Medical Science $2003 \mathbf{1 8} 290-294$

64 Yamagami K, Yoshioka K, Sakai H, Fukumoto M, Yamakita T, Hosoi M et al. Treatment of lymphocytic hypophysitis by highdose methylprednisolone pulse therapy. Internal Medicine 2003 42 168-173.

65 Ezzat S \& Josse RG. Autoimmue hypophysitis. Trends in Endocrinology and Metabolism 19978 74-80.

66 Jabre A, Rosales R, Reed JE \& Spatz EL. Lymphocytic hypophysitis. Journal of Neurology, Neurosurgery and Psychiatry 199763 $672-673$.

67 Lee JH, Laws ER Jr, Guthrie BL, Dina TS \& Nochomovitz LE. Lymphocytic hypophysitis: occurrence in two men. Neurosurgery $199434159-163$.

68 Bottazzo GF, Pouplard A, Florin-Christensen A \& Doniach D. Autoantibodies to prolactin-secreting cells of human pituitary. Lancet 19752 97-101.

69 Wild RA \& Kepley M. Lymphocytic hypophysitis in a patient with amenorrhea and hyperprolactinemia. A case report. Journal of Reproductive Medicine 198631 211-216.

70 Levine SN, Benzel EC, Fowler MR, Shroyer JV 3rd \& Mirfakhraee M. Lymphocytic adenohypophysitis: clinical, radiological, and magnetic resonance imaging characterization. Neurosurgery 198822 937-941.

71 Blisard KS, Pfalzgraf RR \& Balko MG. Sudden death due to lymphoplasmacytic hypophysitis. American Journal of Forensic Medicine and Pathology 199213 207-210.

72 Nishiyama S, Takano T, Hidaka Y, Takada K, Iwatani Y \& Amino N. A case of postpartum hypopituitarism associated with empty sella: possible relation to postpartum autoimmune hypophysitis. Endocrine Journal $1993 \mathbf{4 0} 431-438$.

73 De Bellis A, Colao A, Bizzarro A, Di Salle F, Coronella C, Solimeno $\mathrm{S}$ et al. Longitudinal study of vasopressin-cell antibodies and of hypothalamic-pituitary region on magnetic resonance imaging in patients with autoimmune and idiopathic complete central diabetes insipidus. Journal of Clinical Endocrinology and Metabolism 200287 3825-3829.

74 Pivonello R, De Bellis A, Faggiano A, Di Salle F, Petretta M, Di Somma $\mathrm{C}$ et al. Central diabetes insipidus and autoimmunity: relationship between the occurrence of antibodies to arginine vasopressin-secreting cells and clinical, immunological, and radiological features in a large cohort of patients with central diabetes insipidus of known and unknown etiology. Journal of Clinical Endocrinology and Metabolism $2003 \mathbf{8 8}$ $1629-1636$.
75 Fehn M, Sommer C, Ludecke DK, Plockinger U \& Saeger W. Lymphocytic hypophysitis: light and microscopic findings and correlation to clinical appearance. Endocrine Pathology 19989 $71-78$.

76 Fukuyama T, Koike K, Shiohara M, Kurokawa Y, Sakashita K \& Sawai N. Lymphocytic infundibuloneurohypophysitis during the first remission in acute lymphoblastic leukemia. Rinsho Ketsueki $2000411208-1213$.

77 Vidal S, Rotondo F, Horvath E, Kovacs K \& Scheithauer BW. Immunocytochemical localization of mast cells in lymphocytic hypophysitis. American Journal of Clinical Pathology 2002117 478-483.

78 Ermann J \& Fathman CG. Autoimmune diseases: genes, bugs and failed regulation. Nature Immunology 20012 759-761.

79 McCutcheon IE \& Oldfield EH. Lymphocytic adenohypophysitis presenting as infertility. Case report. Journal of Neurosurgery $199174821-826$.

80 Bottazzo GF, Pujol-Borrell R, Hanafusa T \& Feldmann M. Role of aberrant HLA-DR expression and antigen presentation in induction of endocrine autoimmunity. Lancet $1983 \mathbf{2}$ $1115-1119$.

81 Todd I \& Bottazzo GF. On the issue of inappropriate HLA class II expression on endocrine cells: an answer to a sceptic. Journal of Autoimmunity 19958 313-322.

82 Engelberth O \& Jezkova Z. Autoantibodies in Sheehan's syndrome. Lancet 196511075.

83 Bottazzo GF \& Doniach D. Pituitary autoimmunity: a review. Journal of the Royal Society of Medicine 197871 433-436.

84 Bottazzo GF, McIntosh C, Stanford W \& Preece M. Growth hormone cell antibodies and partial growth hormone deficiency in a girl with Turner's syndrome. Clinical Endocrinology 198012 $1-9$.

85 Scherbaum WA, Schrell U, Gluck M, Fahlbusch R \& Pfeiffer EF. Autoantibodies to pituitary corticotropin-producing cells: possible marker for unfavourable outcome after pituitary microsurgery for Cushing's disease. Lancet 19871 1394-1398.

86 Gluck M \& Scherbaum WA. Substrate specificity for the detection of autoantibodies to anterior pituitary cells in human sera. Hormone and Metabolic Research 199022 541-545.

87 De Bellis A, Bizzarro A, Conte M, Perrino S, Coronella C, Solimeno $\mathrm{S}$ et al. Antipituitary antibodies in adults with apparently idiopathic growth hormone deficiency and in adults with autoimmune endocrine diseases. Journal of Clinical Endocrinology and Metabolism 200388 650-654.

88 Philpot M, Colgan J, Levy R, Holland A, Mirakian R, Richardson CA et al. Prolactin cell autoantibodies and Alzheimer's disease. Journal of Neurology, Neurosurgery and Psychiatry 198548 287-288.

89 Betterle C, Greggio NA \& Volpato M. Clinical review 93: autoimmune polyglandular syndrome type 1. Journal of Clinical Endocrinology and Metabolism 199883 1049-1055.

90 Ludwig H \& Schernthaner G. Multi-organ specific autoimmunity in idiopathic adrenal insufficiency: autosensitization to steroid hormone-producing cells and antigens of the anterior pituitary gland (author's transl). Wiener Klinische Wochenschrift 197890 736-741.

91 Mirakian R, Cudworth AG, Bottazzo GF, Richardson CA \& Doniach D. Autoimmunity to anterior pituitary cells and the pathogenesis of insulin-dependent diabetes mellitus. Lancet $19821755-759$.

92 Bottazzo GF, Mirakian R \& Drexhage HA. Adrenalitis, oophoritis and autoimmune polyglandular disease. In Clinical Immunology: Principles and Practice, edn 1, vol 2, pp 1523-1536. Ed. R-R Rich. St Louis, USA: Mosby Year Book, 1995.

93 Sauter NP, Toni R, McLaughlin CD, Dyess EM, Kritzman J \& Lechan RM. Isolated adrenocorticotropin deficiency associated with an autoantibody to a corticotroph antigen that is not adrenocorticotropin or other proopiomelanocortin-derived peptides. Journal of Clinical Endocrinology and Metabolism $1990 \mathbf{7 0}$ 1391-1397. 
94 Sugiura M, Hashimoto A, Shizawa M, Tsukada M, Saito T, Hayami $\mathrm{H}$ et al. Detection of antibodies to anterior pituitary cell surface membrane with insulin dependent diabetes mellitus and adrenocorticotropic hormone deficiency. Diabetes Research $1987463-66$.

95 Goswami R, Kochupillai N, Crock PA, Jaleel A \& Gupta N. Pitutary autoimmunity in patients with Sheehan's syndrome. Journal of Clinical Endocrinology and Metabolism 200287 4137-4141.

96 Crock P, Salvi M, Miller A, Wall J \& Guyda H. A new method to detect pituitary autoantibodies in growth failure. Hormone Research 199033 (Suppl 3) 12 (abstract 46).

97 Crock P, Salvi M, Miller A, Wall J \& Guyda H. Detection of antipituitary autoantibodies by immunoblotting. Journal of Immunological Methods 1993162 31-40.

98 Crock P. Cytosolic autoantigens in lymphocytic hypophysitis. Journal of Clinical Endocrinology and Metabolism $1998 \mathbf{8 3}$ 609-618.

99 O'Dwyer DT, Smith AI, Matthew ML, Andronicos NM, Ranson M, Robinson PJ et al. Identification of the 49-kDa autoantigen associated with lymphocytic hypophysitis as $\alpha$-enolase. Journal of Clinical Endocrinology and Metabolism 200287 752-757.

100 Laureti S, De Bellis A, Muccitelli VI, Calcinaro F, Bizzarro A, Rossi $\mathrm{R}$ et al. Levels of adrenocortical autoantibodies correlate with the degree of adrenal dysfunction in subjects with preclinical Addison's disease. Journal of Clinical Endocrinology and Metabolism $1998 \mathbf{8 3} 3507-3511$.

101 O'Dwyer DT, Clifton V, Hall A, Smith R, Robinson PJ \& Crock PA. Pituitary autoantibodies in lymphocytic hypophysitis target both gamma- and alpha-enolase - a link with pregnancy? Archives of Physiology and Biochemistry 2002110 94-98.

102 Kobayashi T, Yabe S, Kikuchi T, Kanda T \& Kobayashi I. Presence of anti-pituitary antibodies and GAD antibodies in NIDDM and IDDM. Diabetes Care 199720 864-866.

103 Nishiki M, Murakami Y, Ozawa Y \& Kato Y. Serum antibodies to human pituitary membrane antigens in patients with autoimmune lymphocytic hypophysitis and infundibuloneurohypophysitis. Clinical Endocrinology $200154327-333$.

104 Biro J. TSH binding by globulins from patients with Graves' disease. Endocrinologia Experimentalis 198115 145-153.

105 Raines KB, Baker JR Jr, Lukes YG, Wartofsky L \& Burman KD. Antithyrotropin antibodies in the sera of Graves' disease patients. Journal of Clinical Endocrinology and Metabolism 1985 $61217-222$.

106 Luborsky JL, Visintin I, Boyers S, Asari T, Caldwell B \& DeCherney A. Ovarian antibodies detected by immobilized antigen immunoassay in patients with premature ovarian failure. Journal of Clinical Endocrinology and Metabolism 199070 69-75.

107 Wilkin TJ, Voss L, Tuck A, Bullen H \& Betts P. Autoantibodies to endogenous growth hormone in short children (the Wessex Growth Study). Autoimmunity 199214 67-72.

108 Llera AS, Cardoso AI, Stumpo RR, Martinez AS, Heinrich JJ \& Poskus E. Detection of autoantibodies against hGH in sera of idiopathic hypopituitary children. Clinical Immunology and Immunopathology 199366 114-119.

109 Fetissov SO, Hallman J, Oreland L, Af Klinteberg B, Grenback E, Hulting AL et al. Autoantibodies against alpha-MSH, ACTH, and LHRH in anorexia and bulimia nervosa patients. PNAS 200299 17155-17160.

110 Tanaka S, Tatsumi KI, Takano T, Murakami Y, Takao T, Hashimoto K et al. Detection of autoantibodies against the pituitary-specific proteins in patients with lymphocytic hypophysitis. European Journal of Endocrinology 2002147 767-775.

111 Barbaro D \& Loni G. Lymphocytic hypophysitis and autoimmune thyroid disease. Journal of Endocrinological Investigation 200023 339-340.

112 Presotto F, Pedini B \& Betterle C. Autoimmunità nelle malattie dell'ipofisi e della pineale. In Gli Autoanticorpi, pp 195-201. Ed. C Betterle. Padova: Piccin, 1997.
113 Alvarez A, Cordido F \& Sacristan F. Hypopituitarism due to lymphocytic hypophysitis in a patient with retroperitoneal fibrosis. Postgraduate Medical Journal 199773 732-734.

114 Ahonen P, Myllarniemi S, Sipila I \& Perheentupa J. Clinical variation of autoimmune polyendocrinopathy-candidiasis-ectodermal dystrophy (APECED) in a series of 68 patients. New England Journal of Medicine 1990322 1829-1836.

115 De Bellis A, Bizzarro A, Amoresano Paglionico V, Di Martino S, Criscuolo T, Sinisi AA et al. Detection of vasopressin cell antibodies in some patients with autoimmune endocrine diseases without overt diabetes insipidus. Clinical Endocrinology 1994 40 173-177.

116 Harbuz M. Neuroendocrinology of autoimmunity. International Review of Neurobiology $2002 \mathbf{5 2} 133-161$.

117 Chrousos GP \& Elenkov IJ. Interactions of the endocrine and immune system. In Endocrinology, edn 4, ch. 40, vol. 1, pp 571-586. Eds L-J DeGroot \& JL Jameson. Philadelphia Pennsylvania: WB Saunders Company, 2001.

118 Arnaldi G, de Keyzer Y, Gasc JM, Clauser E \& Bertagna X. Vasopressin receptors modulate the pharmacological phenotypes of Cushing's syndrome. Endocrine Research 1998 24 807-816.

119 Del Rey A \& Besedovsky HO. The cytokine-HPA axis circuit contributes to prevent or moderate autoimmune processes. Zeitschrift fur Rheumatologie $2000 \mathbf{5 9} 31-35$.

120 Maghnie M, Lorini R \& Severi F. Antipituitary antibodies in patients with pituitary abnormalities and hormonal deficiency. Clinical Endocrinology 40 809-810.

121 Amato G, Carella C, Fazio S, La Montagna G, Cittadini A, Sabatini D et al. Body composition, bone metabolism, and heart structure and function in growth hormone (GH)-deficient adults before and after $\mathrm{GH}$ replacement therapy at low doses. Journal of Clinical Endocrinology and Metabolism $1993 \quad 77$ $1671-1676$.

122 Amato G, Izzo G, Salzano I \& Bellastella A. Recombinant human growth hormone treatment at low doses does not significantly change thyroid function in growth hormone deficient adults. Journal of Endocrinological Investigation $199619563-566$.

123 Amato G, Izzo G, La Montagna G \& Bellastella A. Low dose recombinant human growth hormone normalizes bone metabolism and cortical bone density and improves trabecular bone density in growth hormone deficient adults withaut causing adverse effects. Clinical Endocrinology 199645 27-32.

124 McGrail KM, Beyerl BD, Black PM, Klibanski A \& Zervas NT. Lymphocytic adenohypophysitis of pregnancy with complete recovery. Neurosurgery $1987 \mathbf{2 0} 791-793$.

125 Bitton RN, Slavin M, Decker RE, Zito J \& Schneider BS. The course of lymphocytic hypophysitis. Surgical Neurology 1991 $3640-43$.

126 Ozawa Y \& Shishiba Y. Recovery from lymphocytic hypophysitis associated with painless thyroiditis: clinical implications of circulating antipituitary antibodies. Acta. Endocrinologica 1993 128 493-498.

127 Ober KP \& Elster A. Spontaneously resolving lymphocytic hypophysitis as a cause of postpartum diabetes insipidus. Endocrinologist $1994 \mathbf{4} 107-111$.

128 Kristof RA, Van Roost D, Klingmuller D, Springer W \& Schramm J. Lymphocytic hypophysitis: non-invasive diagnosis and treatment by high dose methylprednisolone pulse therapy? Journal of Neurology, Neurosurgery and Psychiatry 199967 398-402.

129 De Bellis A, Bizzarro A, Rossi R, Amoresano Paglionico V, Criscuolo T, Lombardi G et al. Remission of subclinical adrenocortical failure in subjects with adrenal autoantibodies. Journal of Clinical Endocrinology and Metabolism 199376 1002-1007.

130 Schloot N \& Eisenbarth GS. Isohormonal therapy of endocrine autoimmunity. Immunology Today 199516 289-294.

131 De Bellis A, Bizzarro A, Di Martino S, Savastano S, Sinisi AA, Lombardi G et al. Association of arginine vasopressin-secreting cell, steroid-secretng cell, adrenal and islet-cell antibodies in a patient presenting with central diabetes insipidus, empty sella, 
subclinical adrenocortical failure and impaired glucose tolerance. Hormone Research $1995 \mathbf{4 4} 142-146$.

132 De Bellis A, Colao A, Di Salle F, Muccitelli VI, Iorio S, Perrino S et al. A longitudinal study of vasopressin cell antibodies, posterior pituitary function, and magnetic resonance imaging evaluations in subclinical autoimmune central diabetes insipidus. Journal of Clinical Endocrinology and Metabolism $1999 \mathbf{8 4}$ 3047-3051.

133 De Bellis A, Falorni A, Laureti S, Perrino S, Coronella C, Forini F et al. Time course of 21-hydroxylase antibodies and long-term remission of subclinical autoimmune adrenalitis after corticosteroid therapy: case report. Journal of Clinical Endocrinology and Metabolism 200186 675-678.

Received 13 June 2003

Accepted 1 August 2003 